Article

\title{
Impact of Grain Sorghum Polyphenols on Microbiota of Normal Weight and Overweight/Obese Subjects during In Vitro Fecal Fermentation
}

\author{
Danielle Ashley ${ }^{1}$, Daya Marasini ${ }^{1}{ }^{\oplus}$, Cindi Brownmiller ${ }^{1}$, Jung Ae Lee ${ }^{2}$, Franck Carbonero ${ }^{1}$ \\ and Sun-Ok Lee ${ }^{1, *(D)}$ \\ 1 Department of Food Science, Division of Agriculture, University of Arkansas, Fayetteville, AR 72704, USA; \\ dmbenedi@email.uark.edu (D.A.); marasini@uark.edu (D.M.); cbrownm@uark.edu (C.B.); \\ fgcarbon@uark.edu (F.C.) \\ 2 Agricultural Statistics Laboratory, Division of Agriculture, University of Arkansas, Fayetteville, AR 72704, \\ USA; julee@uark.edu \\ * Correspondence: sunok@uark.edu; Tel.: +1-479-575-6921
}

Received: 30 October 2018; Accepted: 14 January 2019; Published: 22 January 2019

\begin{abstract}
The human gut microbiota is considered as a crucial mediator between diet and gut homeostasis and body weight. The unique polyphenolic profile of sorghum bran may promote gastrointestinal health by modulating the microbiota. This study evaluated gut microbiota and modulation of short-chain fatty acids (SCFA) by sorghum bran polyphenols in in vitro batch fermentation derived from normal weight (NW, $n=11)$ and overweight/obese (OO, $n=11)$ subjects' fecal samples. Six separate treatments were applied on each batch fermentation: negative control (NC), fructooligosaccharides (FOS), black sorghum bran extract (BSE), sumac sorghum bran extract (SSE), FOS + BSE, or FOS + SSE; and samples were collected before and after $24 \mathrm{~h}$. No significant differences in total and individual SCFA production were observed between NW and OO subjects. Differential responses to treatment according to weight class were observed in both phyla and genera. Sorghum bran polyphenols worked with FOS to enhance Bifidobacterium and Lactobacillus, and independently stimulated Roseburia and Prevotella $(p<0.05)$. Our results indicate that sorghum bran polyphenols have differential effects on gut health and may positively impact gut ecology, with responses varying depending on weight class.
\end{abstract}

Keywords: sorghum bran polyphenols; gut microbiota; sumac sorghum bran; black sorghum bran; short-chain fatty acids

\section{Introduction}

In the past decades, the human colon has come to light as a hub for microbial activities that impact many aspects of human health. The gut microbiota is composed of hundreds to thousands of species with biological activities including nutrient metabolism, vitamin synthesis, immune modulation, proand anti-microbial activities, and modulation of gut homeostasis [1]. Dysbiosis, or microbial imbalance, has been implicated in a number of chronic progressive conditions, one of which is obesity. More than $70 \%$ of adults in the United States are classified as overweight or obese; not only do these conditions threaten quality of life, but they also increase the risk of chronic diseases such as type 2 diabetes, heart disease, and stroke [2,3]. Evidence from animal and human studies indicates a role of the gut microbiota in body weight maintenance and development of obesity, although exact mechanisms remain unclear [4]. Marked differences in bacterial population have been seen in the microbiota of overweight/obese individuals when compared to normal weight individuals [5-8]. These findings 
implicate the gut microbiota as a potential target of nutritional therapies to prevent/reduce weight gain and obesity.

While most food consumed is digested and absorbed in the stomach and small intestine, complex carbohydrates such as resistant starch and fiber reach the colon where they are utilized by the gut microbiota [9]. These compounds are fermented by certain species to produce short-chain fatty acids (SCFA) which have numerous health implications including body weight maintenance [8,10-12]. Prebiotics were previously defined as "selectively fermented ingredient(s) that result in specific changes in the composition and/or activity of the gastrointestinal microbiota, thus conferring benefit(s) upon host health" and the compounds that fit these criteria were limited to mainly inulin, galactooligosaccharides (GOS), and fructooligosaccharides (FOS) [13]. In 2017 however, prebiotics were redefined as "a substrate that is selectively utilized by host microorganisms conferring a health benefit" [14]. This new definition may allow for inclusion of non-carbohydrate foods that do not undergo fermentation but are utilized by beneficial species in the gut, thus enhancing their expansion and positive health benefits. Such compounds include polyphenols.

Polyphenols are biologically active compounds produced by metabolic pathways in plants, with numerous roles including pathogen protection, antimicrobial, and antioxidant activities [15]. Most polyphenols consumed by humans are polymerized and/or glycosylate. These high molecular weight compounds reach the colon where they are broken down by the gut microbiota to smaller, absorbable compounds [16]. Grain sorghum (Sorghum bicolor L. Moench) commonly called sorghum, is the world's fifth highly produced cereal crop, far behind the top four (rice, corn, wheat, and barley) but commonly grown in specific areas. Sorghum contains various classes of polyphenols, which are in the bran fraction [17]. The polyphenol composition of sorghum bran varies with its color, with sumac varieties rich in proanthocyanidins and black varieties rich in 3-deoxyanthocyanins, which include luteolinidin and apigeninidin [18]. Though previous studies have identified positive modulatory effects of polyphenols from polyphenol-rich foods on the human gut microbiota [19-24], to our knowledge no research has been conducted with sorghum polyphenol extracts. The objectives of this research were to characterize the major polyphenol components of two sorghum brans, and to evaluate the change of gut microbiota composition and the effect on SCFA production in response to sorghum bran polyphenols in fecal samples from normal weight (NW) and overweight/obese (OO) subjects.

\section{Materials and Methods}

\subsection{Sorghum Brans, Standards, and Reagents}

Black and sumac sorghum brans were purchased from local market and $\mathrm{Nu}$ Life Market (Scott City, KS, USA) and fructooligosaccharides (FOS) from Megazyme International Ireland Ltd. (Wicklow, Ireland). Folin-Ciocalteu's reagent, 4-dimethylaminocinnamaldehyde (DMAC), 2,2diphenyl-1-picrylhydrazyl (DPPH), butyric acid, propionic acid, and acetic acid were obtained from Sigma-Aldrich (St. Louis, MO, USA). Luteolinidin and apigeninidin were from Chromadex (Irvine, CA, USA).

\subsection{Preparation of Polyphenols from Sorghum Bran Samples}

Polyphenol extractions were performed according to Awika et al. [18] with modifications. Defatted sorghum bran samples $(5 \mathrm{~g})$ and extracting solvent $(1 \% \mathrm{HCl}$ in $70 \%$ methanol) were mixed at a ratio of 1:60. Mixtures were stirred at room temperature for $2 \mathrm{~h}$ and filtered through Whatman No. 42 filter paper (GE Healthcare, Amersham, UK). Solvent was removed using rotary evaporation at $30^{\circ} \mathrm{C}$ and the aqueous filtrate applied to a pre-activated C-18 solid phase extraction (SPE) column (Grace Davidson Discovery Sciences, Deerfield, IL, USA). Sugars were eluted with $100 \mathrm{~mL}$ of water and discarded; then the remaining polyphenols were eluted with $100 \mathrm{~mL}$ of methanol. After elution of polyphenols, $50 \mathrm{~mL}$ of deionized water were then added to methanolic extract and methanol was removed through rotary evaporation at $30^{\circ} \mathrm{C}$. The concentrated aqueous extract was then frozen and 
subsequently lyophilized in a VirTis Benchtop SLC freeze dryer (SP Industries, Warminster, PA, USA). Resulting powdered polyphenol extracts, black sorghum bran extract (BSE), and sumac sorghum bran extract (SSE), were then pooled and stored in a desiccator at $-4{ }^{\circ} \mathrm{C}$ until further analysis. Dried polyphenol extracts were used as substrates in the in vitro fecal fermentation experiment.

\subsection{Analysis of Polyphenol Content and Antioxidant Activity}

Total polyphenol content of sorghum bran extracts (BSE and SSE) was determined using the Folin-Ciocalteu assay according to Singleton and Rossi [25] with minor modifications. Standards were prepared using gallic acid in concentrations of 3.125, 6.25, 12.5, 25, 50, and $100 \mu \mathrm{g} / \mathrm{g}$. BSE and SSE were dissolved for a dilution of 8000 -fold. In a 48 -well plate, $0.1 \mathrm{~mL}$ sample or standard, $0.5 \mathrm{~mL}$ of $0.2 \mathrm{~N}$ Folin-Ciocalteu's reagent, and $0.4 \mathrm{~mL}$ of $7.5 \% \mathrm{Na}_{2} \mathrm{CO}_{3}$ were combined. The plate was incubated at room temperature for $2 \mathrm{~h}$ and the absorbance at $760 \mathrm{~nm}$ was determined in a Synergy TT microplate reader (BioTek Instruments, Winooski, VT, USA). All samples and standards were measured in triplicate. Concentration was determined by plotting against a gallic acid standard curve and results were thus expressed in gallic acid equivalents (GAE).

Total proanthocyanidin content was determined using the 4-dimethylaminocinnamaldehyde (DMAC) assay [26]. Standards were prepared using catechin and ethanol (95\%) at concentrations of $0.125,6.25,12.5,25,50$, and $100 \mu \mathrm{g} / \mathrm{g}$. In a 48 -well plate, $0.15 \mathrm{~mL}$ of sample (BSE and SSE in ethanol for a dilution of 8000 -fold) or standard and $0.75 \mathrm{~mL}$ of $5.7 \mathrm{~N}$ DMAC solution were combined, all in at least triplicate. Plates were read immediately at $640 \mathrm{~nm}$ in microplate reader. Concentration was determined by plotting against a catechin standard curve and expressed in catechin equivalents.

For quantitative analysis of 3-deoxyanthocyanins (3-DXA) a Beckman Coulter (Fullerton, CA, USA) System Gold HPLC system was used. The system was equipped with a 126 pump, a 168 Detector, and a 508 autosampler. The software used for data collection and integration was 32 Karat 8 . A $250 \times 4.6 \mathrm{~mm}$ i.d. C18 column (YMC America Inc, Allentown, PA, USA) was used for separation of 3-DXA in sorghum and standards. The mobile phase consisted of A: $5 \%$ formic acid in water, and $\mathrm{B}: 100 \%$ methanol. Flow rate was $1 \mathrm{~mL} \mathrm{~min}^{-1}$ and injection volume was $30 \mu \mathrm{L}$. The mobile phase gradient of Cho et al. [27] was used, with minor modifications: 0-60 min: 2-60\% B, 60-61 min: $60-2 \%$ B, 61-66 min: 2\% B, 66-75 min: 2-0\% B. Wavelengths monitored were 280, 340, and $480 \mathrm{~nm}$. Apigeninidin and luteolinidin were identified and quantified using standard curves.

Antioxidant properties were determined using the free radical 2,2- diphenyl-1-picrylhydrazyl (DPPH) assay according to Brand-Williams et al. [28]. DPPH solution was prepared by dissolving in methanol $(0.15 \mathrm{mM})$ and stored at $-20^{\circ} \mathrm{C}$ between uses. Serial dilutions of BSE and SSE (1-140 ppm) were prepared in methanol. DPPH solution $(0.95 \mathrm{~mL})$ was added to $0.05 \mathrm{~mL}$ extracts of varying concentrations and shaken. Plates were read in microplate reader at $30 \mathrm{~min}$ at $517 \mathrm{~nm}$. Effective concentration to reduce the radical by $50 \%\left(\mathrm{EC}_{50}\right)$ was determined for both bran extracts and reported as $\mu \mathrm{g}$ gallic acid equivalents per gram. All samples and standards were plated in at least triplicate.

\subsection{Human Fecal Fermentation}

After approval of the study by the International Review Board (University of Arkansas; IRB \#17-02-433), 22 subjects were recruited from the North West Arkansas area: 11 normal weight (NW, body mass index $(\mathrm{BMI})<25)$ and 11 overweight/obese $(\mathrm{OO}, \mathrm{BMI} \geq 25)$ subjects. Exclusion criteria included tobacco use, digestive disease, fasting blood glucose (FBG $\geq 100 \mathrm{mg} / \mathrm{dL}$ ), current medications, and antibiotic use within the past six months. Consent and screening forms as well as food frequency questionnaires were filled out during screening sessions. FFQ (Food Frequency Questionnaire) responses were analyzed using Axxya System Nutritionist Pro ${ }^{\mathrm{TM}}$ software version 4.3.0 (Stafford, TX, USA) based on USDA References. No significant differences in macro- and micro-nutrient intake were observed between weight class groups or genders. Participant characteristics are provided in Table 1. Selected participants were given a stool collection kit and delivered samples within an hour of defecation. Fecal samples were transferred to anaerobic chamber immediately for fermentation experiment. 
Fecal fermentation medium was prepared according to Yang et al. [29]. One liter of anerobic fermentation medium was composed of yeast extract ( 2 g; Alfa Aesar, Ward Hill, MA, USA), peptone ( 2 g; Fisher Scientific, Waltham, WA, USA), bile salts ( $0.5 \mathrm{~g}$; Oxoid, Hampshire, UK), $\mathrm{NaHCO}_{3}(2 \mathrm{~g}$ ), $\mathrm{NaCl}(0.1 \mathrm{~g}), \mathrm{K}_{2} \mathrm{HPO}_{4}(0.08 \mathrm{~g}), \mathrm{MgSO}_{4} .7 \mathrm{H}_{2} \mathrm{O}(0.01 \mathrm{~g}), \mathrm{CaCl}_{2} \cdot 6 \mathrm{H}_{2} \mathrm{O}(0.01 \mathrm{~g})$, L-cysteine hydrochloride ( $0.5 \mathrm{~g}$; Sigma, St. Louis, MO, USA), vitamin K (10 $\mu \mathrm{L}$; Sigma, St. Louis, MO, USA), bovine hemin ( $50 \mathrm{mg}$; Sigma, St. Louis, MO, USA), Tween $80(2 \mathrm{~mL})$, and $0.025 \%(w / v)$ resazurin solution. To prepare fecal slurry, $2 \mathrm{~g}$ fecal sample was added to $20 \mathrm{~mL}$ phosphate-buffered saline, vortexed to homogenization, and filtered through four layers of cotton gauze. After the analyses of total polyphenol content, the amount of BSE and SSE was calculated taking into account the grape extract and black tea extract $(0.6-1 \mathrm{~g} / \mathrm{L})$. Within an anaerobic chamber, $14 \mathrm{~mL}$ of sterile fermentation medium were inoculated with $1 \mathrm{~mL}$ of fecal slurry and treated with either no substrate (negative control, NC), FOS, BSE, SSE, FOS + BSE, and FOS + SSE. The final concentration of FOS and grain sorghum bran extract (BSE and SSE) was $5 \mathrm{~g} / \mathrm{L}$ and $1 \mathrm{~g} / \mathrm{L}$, respectively. Test tubes were incubated at $37^{\circ} \mathrm{C}$ and aliquots $(\sim 3 \mathrm{~mL})$ taken at the time points $0,6,12,18$, and $24 \mathrm{~h}$. Aliquots were added to $0.2 \mathrm{~mL}$ of $2 \mathrm{M} \mathrm{KOH}$ stop solution and stored at $-80{ }^{\circ} \mathrm{C}$ until further analysis.

Table 1. Subject characteristics

\begin{tabular}{cccccc}
\hline \multirow{2}{*}{ All $(\boldsymbol{n}=\mathbf{2 2})$} & \multicolumn{2}{c}{ Normal Weight } & \multicolumn{2}{c}{ Overweight/Obese } \\
\cline { 3 - 5 } & & Male $(\boldsymbol{n}=\mathbf{5})$ & Female $(\boldsymbol{n}=\mathbf{6})$ & Male $(\boldsymbol{n}=\mathbf{5})$ & Female $(\boldsymbol{n}=\mathbf{6})$ \\
\hline Age (years) & $29.0 \pm 6.7$ & $29.4 \pm 4.8$ & $24.2 \pm 2.1$ & $28.2 \pm 3.5$ & $34.2 \pm 9.7$ \\
BMI (kg/m $\left.{ }^{2}\right)$ & $27.1 \pm 5.5$ & $23.0 \pm 0.7$ & $22.2 \pm 1.2$ & $30.9 \pm 2.9$ & $32.2 \pm 5.4$ \\
FBG $(\mathrm{mg} / \mathrm{dL})$ & $92.1 \pm 4.9$ & $92.9 \pm 3.1$ & $90.6 \pm 5.0$ & $92.6 \pm 6.9$ & $96.3 \pm 3.3$ \\
\hline
\end{tabular}

Data are expressed as mean \pm standard deviation (SD). BMI: body mass index, FBG: fasting blood glucose.

\subsection{Short-Chain Fatty Acid (SCFA) Analysis}

Short-chain fatty acids (SCFA) content was determined for all samples at all time point using the method of Bourquin et al. [30] with modification. After thawing at room temperature, $450 \mu \mathrm{L}$ of samples were combined with $50 \mu \mathrm{L}$ of a prepared solution containing $50 \mathrm{~g}$ meta-phosphoric acid and $1.6 \mathrm{~g} \mathrm{CuSO}_{4} / \mathrm{L}$, and $314.6 \mu \mathrm{L}$ 4-methyl valeric acid (internal standard). After incubation at room temperature for $10 \mathrm{~min}$, the mixture was centrifuged at 11,500 rpm for $5 \mathrm{~min}$ and the supernatant collected for analysis. SCFA analysis was performed using a Varian CP-3800 GC (Agilent, Santa Clara, CA, USA) with a CP-8400 autosampler and a HP-FFAP (High Polarity for the analysis of Free Fatty Acids and Phenols) modified polyethylene glycol $(25 \mathrm{~m} \times 32 \mathrm{~mm})$ column. One $\mu \mathrm{L}$ of sample was injected with a split of $30: 1$ and a flow rate of $1.3 \mathrm{~mL} / \mathrm{min}$. The gradient used was $3{ }^{\circ} \mathrm{C} / \mathrm{min}$ from $65^{\circ} \mathrm{C}$ to $110^{\circ} \mathrm{C}$ and $8^{\circ} \mathrm{C} / \mathrm{min}$ until $150^{\circ} \mathrm{C}$. Total and individual SCFA were quantified against reference standards for butyric acid (BA), propionic acid (PA), and acetic acid (AA).

\subsection{Microbial Analysis}

Changes of microbiota profiles in response to treatments were determined by analyzing bacterial DNA of samples from time point 0 and $24 \mathrm{~h}$ following protocols previously described [31]. DNA was extracted using the QIAamp Fast DNA Stool Mini Kit (Qiagen, Gaithersburg, MD, USA). The V4 region of the bacterial 16S-rRNA gene was amplified by polymerase chain reaction (PCR) in Eppendorf Mastercycler Pro S (Eppendorf, Hamburg, Germany) using AccuPrime Pfx SuperMix and V4 index primers [32]. After confirming the amplification through agarose gel electrophoresis, DNA samples were normalized with SequalPrep Normalization Plate Kit (Thermo Fisher Scientific, Waltham, WA, USA). The concentration of final pooled library of the V4 region of 16S-rRNA gene of bacteria was sequenced utilizing the Illumina MiSeq platform [32]. Fastq files generated through Illumina were demultiplexed and quality filtered, operational taxonomic units (OTUs) assigned using SILVA database, and the data processed through Mothur 1.40.1 [33]. 


\subsection{Experimental Design and Statistical Analysis}

Each of the 22 subjects received all six treatments (NC, FOS, BSE, SSE, FOS + BSE, FOS + SSE). Therefore, the statistical analysis was performed for the randomized complete block design (RCB), in which the effect of six treatments was tested with subjects as blocks. We note that the analysis of variance (ANOVA) approach for RCB seriously violated the assumptions of normality and equal variance in our diagnostic procedures. Alternatively, Friedman test was used, known as a distribution-free rank sum test for $\mathrm{RCB}$, followed by pairwise comparisons among six treatments at different time points: $6,12,18,24 \mathrm{~h}$ for SCFA data and $0,24 \mathrm{~h}$ for microbiota data, respectively. The time effect ( 0 vs. $24 \mathrm{~h}$ ) was tested using a Wilcoxon signed rank sum test, as an alternative to a paired $t$-test, if there was a significant increase/decrease in relative abundance among 22 subjects. The effect of weight class (NW vs. OO with 11 subjects each) was tested using a Mann-Whitney test, as an alternative to two-sample $t$-test, under different treatments. All tests were nonparametric to avoid any controversial assumption for small sample size. The false discovery rate adjustment for the $p$-value was conducted as appropriate. Non-metric multidimensional scaling (NMDS) was utilized to analyze similarities in bacterial communities between treatments. PAST 3.15 was used for NMDS and analysis of similarities (ANOSIM) according to the Bray-Curtis index. The statistical results were reported at 0.05 or 0.01 levels of significance. All data analyses were conducted using statistical software SPSS (IBM, Armonk, NY, USA) and R version 3.3.3 (R core Team, Vienna, Austria).

\section{Results}

\subsection{Polyphenol Profile and Antioxidant Properties of Sorghum Bran Extracts}

Total polyphenols and proanthocyanidins were significantly higher in sumac sorghum bran extract (SSE), and 3-deoxyanthocyanins in black sorghum bran extract $(p<0.01)$ (Table 2). Radical scavenging capability was assessed using the DPPH radical, and both black (BSE, $274.0 \pm 20.3 \mu \mathrm{g}$ gallic acid equivalent (GAE)/g) and sumac (SSE, $269.5 \pm 21.0 \mu \mathrm{g}$ GAE/g) sorghum bran extracts demonstrated antioxidant capabilities with no significant differences between the two.

Table 2. Major polyphenol profile of black and sumac sorghum bran extracts.

\begin{tabular}{lcc}
\hline & BSE & SSE \\
\hline Polyphenols (mg gallic acid equiv/g extract) & $321.5 \pm 2.7$ & $571.7 \pm 6.0^{*}$ \\
Proanthocyanidins (mg catechin equiv/g extract) & $8.4 \pm 1.4$ & $86.9 \pm 1.1^{*}$ \\
3-Deoxyanthocyanins (mg/g extract) & $10.1 \pm 0.3^{*}$ & $2.0 \pm 0.4$ \\
Luteolinidin & $9.3 \pm 0.4^{*}$ & $2.0 \pm 0.4$ \\
Apigeninidin & $0.9 \pm 0.1^{*}$ & $\mathrm{ND}$ \\
\hline
\end{tabular}

Data are expressed as mean \pm standard deviation (SD). ${ }^{*}$ Indicates significant difference between black and suman bran extracts. $p<0.01 . n=8$. BSE: black sorghum bran extract, SSE: sumac sorghum bran extract, ND: not detected.

\subsection{Short-Chain Fatty Acid Production}

No significant differences in total and individual SCFA production was observed between NW and OO. Total SCFA concentration was significantly increased by FOS and FOS + SSE compared to the NC, BSE, and SSE at $6 \mathrm{~h}(p<0.05)$ (Figure 1). SSE resulted in lower levels of total SCFA from time points $12 \mathrm{~h}$ to $24 \mathrm{~h}$ (Figure 1 ).

FOS alone increased acetic acid (AA) compared to NC, BSE, SSE, and FOS + BSE at $6 \mathrm{~h}$, and SSE displayed lower concentrations compared to FOS at $12 \mathrm{~h}(p<0.05)$ (Figure 1). BSE increased AA concentration compared to SSE and FOS + SSE at time points of $18 \mathrm{~h}$ and $24 \mathrm{~h}(p<0.05)$.

Incremental propionic acid (PA) concentration was generally higher in NW than $\mathrm{OO}$, though not significantly. SSE caused lower concentrations of PA at 12,18 , and 24 h compared to NC $(p<0.05)$ (Figure 1). 
Incremental butyric acid (BA) concentrations in FOS and FOS + SSE treatments were significantly higher than NC, BSE, and SSE at $6 \mathrm{~h}$ and $12 \mathrm{~h}(p<0.05)$ (Figure 1). FOS increased BA compared to NC, BSE, and SSE at all time points $(p<0.05)$. Sorghum extracts alone did not alter BA concentrations.

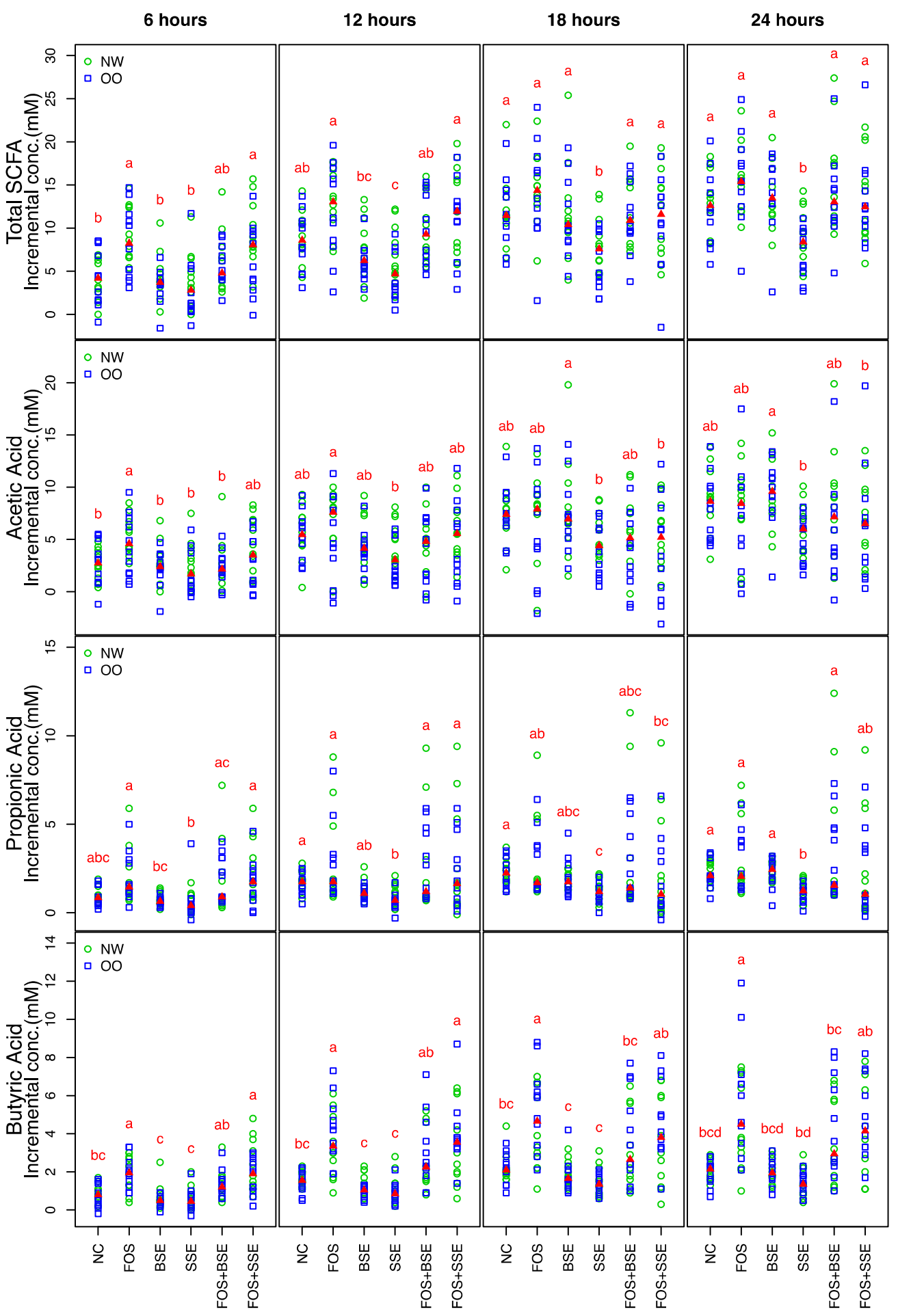

Figure 1. Total and individual SCFA during fermentation by treatment in both normal weight (NW, $n=11)$ and overweight/obese (OO, $n=11)$ samples. Different letters indicate significant differences between treatments, achieved by the Friedman test and its post hoc multiple comparisons at 0.05 level of significance. The medians are marked with red triangles. The weight classes (NW vs. OO) are labeled by green circles and blue squares, respectively. NC: negative control, FOS: fructooligosaccharides, BSE: black sorghum bran extract, SSE: sumac sorghum bran extract; SCFA: short-chain fatty acids. 


\subsection{General Changes in the Microbiota}

After DNA extraction and sequencing of 264 samples, a total of 5,062,231 high quality reads were obtained for analysis of microbial populations. Overall distribution of microbiota, the comparison between NW and OO, and a change between time point $0 \mathrm{~h}$ and $24 \mathrm{~h}$ are shown in Figure 2 . At the phylum level, the fermentation was dominated by Bacteroidetes, in which we observed a significant drop over the past $24 \mathrm{~h}$, a significant difference between NW and $\mathrm{OO}$ at $24 \mathrm{~h}$, and an insignificant difference between NW and $\mathrm{OO}$ at $0 \mathrm{~h}$ under no treatment (negative control, bottom left panel). A similar interpretation is possible for all microbiota in both phylum and genera. This analysis narrows down our focus on certain microbiota, and shows how we stratified the situations for weight class and time effect to be tested. The results for all microbiota are summarized in Tables 3 and 4 .

Non-metric multidimensional scaling (NMDS) plots revealed no differences in bacterial communities between treatments at time point 0 (Figure $3 \mathrm{~A}$ ), however after $24 \mathrm{~h}$ a clear separation was seen between the NC and FOS-containing treatments $(p<0.05)$ (Figure 3B). Sorghum extracts alone did not significantly impact bacterial communities compared to the negative control.

(a) Phylum

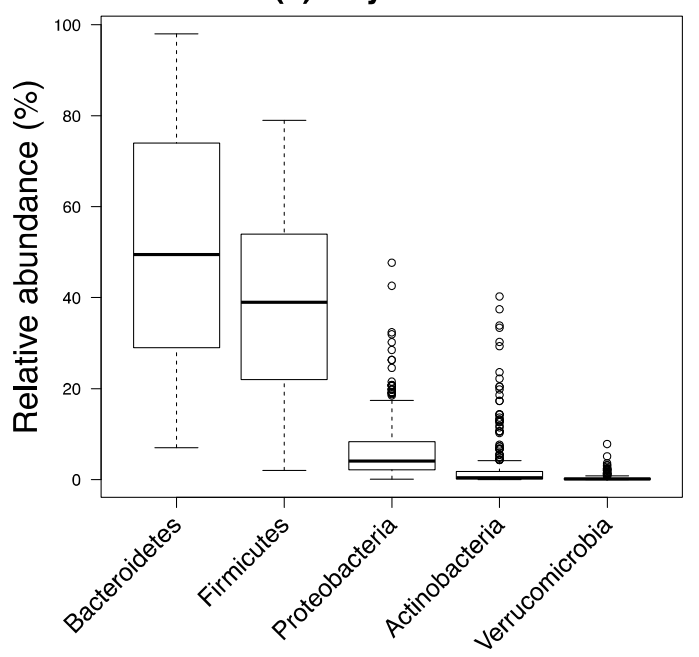

(c) Bacteroidetes

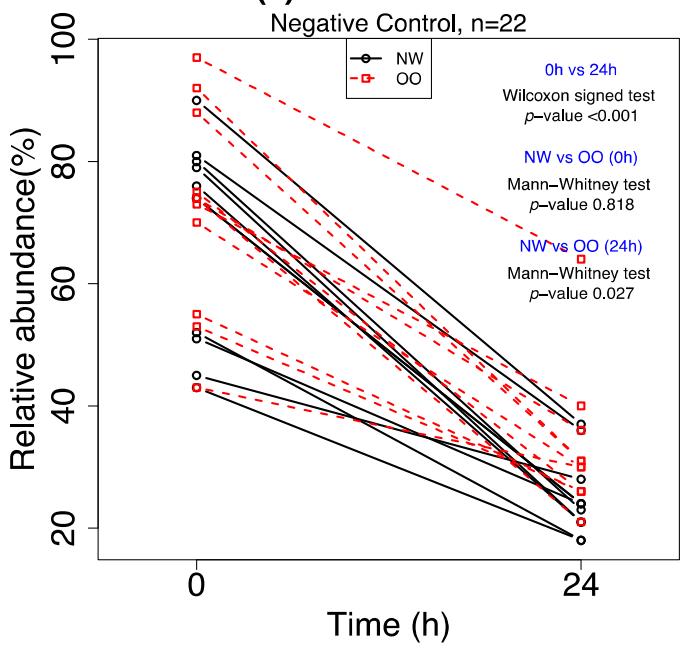

(b) Genera

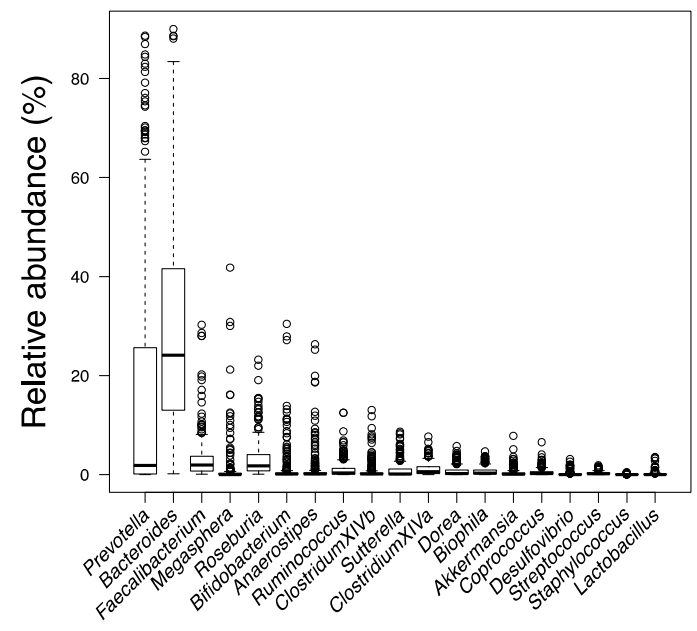

(d) Prevotella

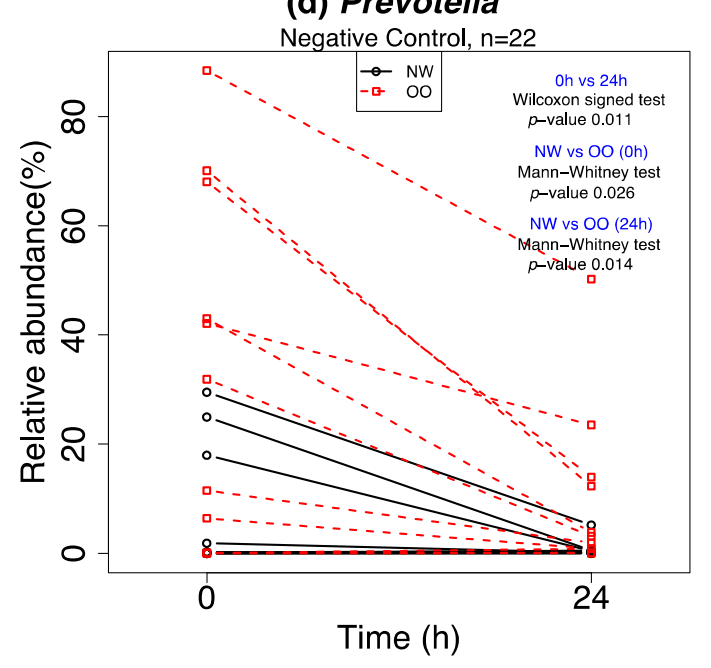

Figure 2. Dynamics of microbiota (phylum and genera level) in in vitro fermentation. In (a,b), the distribution of microbiota is depicted in the boxplot sorted by largest variance. In (c,d), the time effect, $0 \mathrm{~h}$ vs. $24 \mathrm{~h}$, is shown and tested by a Wilcoxon signed test, and the group difference between NW and $\mathrm{OO}$ is tested by a Mann-Whitney test under the negative control $(n=22)$ for two selected microbiota. 
Table 3. The effects of time and weight class in dominant phyla.

\begin{tabular}{|c|c|c|c|c|}
\hline Microbiota & Treatment & $\begin{array}{c}\text { Change in } 24 \mathrm{~h} \\
\text { Relative Abundance (\%) }\end{array}$ & $\begin{array}{c}\text { Wilcoxon Signed Test } \\
(0 \mathrm{~h} \text { vs. } 24 \mathrm{~h}) \\
q \text {-Value } t\end{array}$ & $\begin{array}{c}\text { Mann-Whitney Test } \\
\text { (NW vs. OO) at } 24 \mathrm{~h} \\
q \text {-Value } t\end{array}$ \\
\hline Bacteroidetes & $\mathrm{NC}$ & -41.10 & $<0.001$ & 0.136 \\
\hline Bacteroidetes & FOS & -43.50 & $<0.001$ & 0.085 \\
\hline Bacteroidetes & BSE & -23.60 & $<0.001$ & 0.085 \\
\hline Bacteroidetes & SSE & -31.00 & $<0.001$ & 0.085 \\
\hline Bacteroidetes & $\mathrm{FOS}+\mathrm{BSE}$ & -35.10 & $<0.001$ & 0.177 \\
\hline Bacteroidetes & $\mathrm{FOS}+\mathrm{SSE}$ & -32.10 & $<0.001$ & 0.246 \\
\hline Firmicutes & $\mathrm{NC}$ & 22.40 & 0.001 & 0.491 \\
\hline Firmicutes & FOS & 32.00 & $<0.001$ & 0.489 \\
\hline Firmicutes & BSE & 14.00 & 0.006 & 0.107 \\
\hline Firmicutes & SSE & 19.70 & $<0.001$ & 0.180 \\
\hline Firmicutes & FOS + BSE & 24.10 & $<0.001$ & 0.491 \\
\hline Firmicutes & FOS + SSE & 23.80 & 0.002 & 0.974 \\
\hline Proteobacteria & $\mathrm{NC}$ & 17.40 & $<0.001$ & 0.640 \\
\hline Proteobacteria & FOS & 1.00 & 1.000 & 0.489 \\
\hline Proteobacteria & BSE & 7.70 & $<0.001$ & 0.491 \\
\hline Proteobacteria & SSE & 10.00 & $<0.001$ & 0.491 \\
\hline Proteobacteria & FOS + BSE & -1.40 & 0.034 & 0.180 \\
\hline Proteobacteria & $\mathrm{FOS}+\mathrm{SSE}$ & -1.20 & 0.058 & 0.190 \\
\hline Actinobacteria & $\mathrm{NC}$ & 0.30 & 0.003 & 0.825 \\
\hline Actinobacteria & FOS & 10.30 & $<0.001$ & 0.491 \\
\hline Actinobacteria & BSE & 0.70 & $<0.001$ & 0.061 \\
\hline Actinobacteria & SSE & 0.60 & $<0.001$ & 0.180 \\
\hline Actinobacteria & FOS + BSE & 11.80 & $<0.001$ & 0.280 \\
\hline Actinobacteria & $\mathrm{FOS}+\mathrm{SSE}$ & 9.20 & $<0.001$ & 0.180 \\
\hline Verrucomicrobia & $\mathrm{NC}$ & -0.10 & 0.867 & 0.926 \\
\hline Verrucomicrobia & FOS & -0.10 & 0.076 & 0.636 \\
\hline Verrucomicrobia & BSE & 0.60 & 0.079 & 0.489 \\
\hline Verrucomicrobia & SSE & 0.00 & 0.463 & 0.926 \\
\hline Verrucomicrobia & FOS + BSE & -0.10 & 0.949 & 0.378 \\
\hline Verrucomicrobia & $\mathrm{FOS}+\mathrm{SSE}$ & 0.10 & 0.215 & 0.491 \\
\hline
\end{tabular}

+ adjusted $p$-value by false discovery rate. A change in relative abundance over $24 \mathrm{~h}$ was tested using a Wilcoxon signed test. A Mann-Whitney test was used to test the difference between NW (normal weight) vs. OO (overweight/obesity) at $24 \mathrm{~h}$ under each treatment. NC: negative control, FOS: fructooligosaccharides, BSE: black sorghum bran extract, SSE: sumac sorghum bran extract.

Table 4. The effects of time and weight class at the genus level.

\begin{tabular}{|c|c|c|c|c|}
\hline Microbiota & Treatment & $\begin{array}{l}\text { Change in } 24 \mathrm{~h} \\
\text { Relative Abundance (\%) }\end{array}$ & $\begin{array}{c}\text { Wilcoxon Signed Test } \\
(0 \mathrm{~h} \text { vs. } 24 \mathrm{~h}) \\
q \text {-Value } t\end{array}$ & $\begin{array}{c}\text { Mann-Whitney Test } \\
\text { (NW vs. OO) at } 24 \mathrm{~h} \\
q \text {-Value } t\end{array}$ \\
\hline Prevotella & $\mathrm{NC}$ & -14.50 & 0.022 & 0.557 \\
\hline Prevotella & FOS & -8.00 & 0.010 & 0.557 \\
\hline Prevotella & BSE & -7.10 & 0.145 & 0.557 \\
\hline Prevotella & SSE & -11.90 & 0.017 & 0.557 \\
\hline Prevotella & FOS + BSE & -7.60 & 0.087 & 0.639 \\
\hline Prevotella & $\mathrm{FOS}+\mathrm{SSE}$ & -7.00 & 0.057 & 0.639 \\
\hline Bacteroides & $\mathrm{NC}$ & -23.90 & 0.001 & 0.779 \\
\hline Bacteroides & FOS & -27.90 & $<0.001$ & 0.727 \\
\hline Bacteroides & BSE & -14.60 & 0.019 & 0.800 \\
\hline Bacteroides & SSE & -14.40 & 0.028 & 0.755 \\
\hline Bacteroides & FOS + BSE & -22.50 & 0.001 & 0.721 \\
\hline Bacteroides & FOS + SSE & -21.40 & 0.003 & 0.719 \\
\hline Bifidobacterium & $\mathrm{NC}$ & 0.10 & 0.059 & 0.875 \\
\hline Bifidobacterium & FOS & 3.50 & 0.001 & 0.579 \\
\hline Bifidobacterium & BSE & 0.10 & 0.018 & 0.755 \\
\hline Bifidobacterium & SSE & 0.20 & 0.016 & 0.589 \\
\hline Bifidobacterium & FOS + BSE & 5.30 & $<0.001$ & 0.638 \\
\hline Bifidobacterium & $\mathrm{FOS}+\mathrm{SSE}$ & 4.30 & $<0.001$ & 0.557 \\
\hline Lactobacillus & $\mathrm{NC}$ & 0.00 & 0.919 & 0.721 \\
\hline Lactobacillus & FOS & 0.20 & 0.300 & 0.957 \\
\hline Lactobacillus & BSE & 0.10 & 0.059 & 0.782 \\
\hline Lactobacillus & SSE & 0.10 & 0.025 & 0.721 \\
\hline Lactobacillus & FOS + BSE & 0.30 & 0.011 & 0.755 \\
\hline Lactobacillus & $\mathrm{FOS}+\mathrm{SSE}$ & 0.30 & 0.004 & 1 \\
\hline
\end{tabular}


Table 4. Cont.

\begin{tabular}{|c|c|c|c|c|}
\hline Microbiota & Treatment & $\begin{array}{c}\text { Change in } 24 \mathrm{~h} \\
\text { Relative Abundance (\%) }\end{array}$ & $\begin{array}{c}\text { Wilcoxon Signed Test } \\
(0 \mathrm{~h} \text { vs. } 24 \mathrm{~h}) \\
q \text {-Value } t\end{array}$ & $\begin{array}{c}\text { Mann-Whitney Test } \\
\text { (NW vs. OO) at } 24 \mathrm{~h} \\
q \text {-Value } t\end{array}$ \\
\hline Faecalibacterium & $\mathrm{NC}$ & -0.40 & 0.314 & 0.579 \\
\hline Faecalibacterium & FOS & -2.10 & 0.007 & 0.721 \\
\hline Faecalibacterium & BSE & -3.90 & 0.001 & 0.579 \\
\hline Faecalibacterium & SSE & -3.10 & 0.017 & 0.684 \\
\hline Faecalibacterium & FOS + BSE & -3.50 & $<0.001$ & 0.557 \\
\hline Faecalibacterium & FOS + SSE & -2.90 & 0.145 & 0.651 \\
\hline Roseburia & $\mathrm{NC}$ & -0.40 & 0.251 & 0.876 \\
\hline Roseburia & FOS & 1.00 & 0.991 & 0.930 \\
\hline Roseburia & BSE & 0.10 & 0.893 & 0.755 \\
\hline Roseburia & SSE & 1.20 & 0.278 & 0.649 \\
\hline Roseburia & FOS + BSE & 1.40 & 0.341 & 0.972 \\
\hline Roseburia & FOS + SSE & 2.10 & 0.327 & 0.800 \\
\hline Anaerostipes & $\mathrm{NC}$ & 0.30 & 0.047 & 0.755 \\
\hline Anaerostipes & FOS & 3.80 & 0.001 & 0.972 \\
\hline Anaerostipes & BSE & 0.40 & 0.077 & 0.755 \\
\hline Anaerostipes & SSE & 0.70 & 0.057 & 0.779 \\
\hline Anaerostipes & FOS + BSE & 3.40 & $<0.001$ & 0.957 \\
\hline Anaerostipes & $\mathrm{FOS}+\mathrm{SSE}$ & 4.10 & $<0.001$ & 1 \\
\hline
\end{tabular}

+ adjusted $p$-value by false discovery rate. A change in relative abundance over $24 \mathrm{~h}$ was tested using a Wilcoxon signed test. A Mann-Whitney test was used to test the difference between NW (normal weight) vs. OO (overweight/obesity) at $24 \mathrm{~h}$ under each treatment. NC: negative control, FOS: fructooligosaccharides, BSE: black sorghum bran extract, SSE: sumac sorghum bran extract.
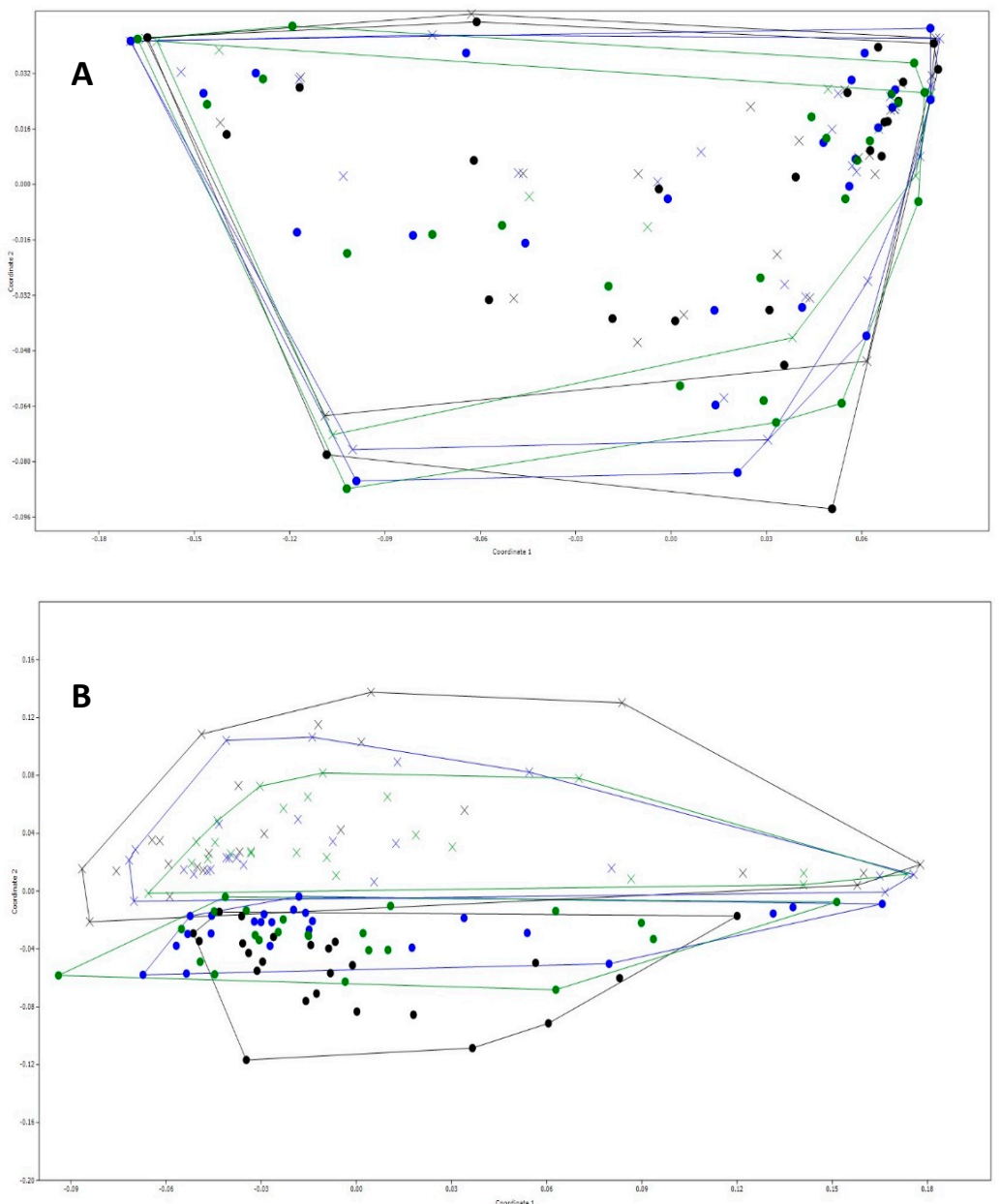

Figure 3. Non-metric multidimensional scaling (NMDS) plot comparing bacterial communities between treatments in both groups combined $(p<0.05)$. (A) $0 \mathrm{~h}$ and (B) $24 \mathrm{~h}$. •: negative control (NC), $\mathbf{x}$ : fructooligosaccharides (FOS), $\bullet$ : black sorghum bran extract (BSE), •: sumac sorghum bran extract (SSE), $x:$ FOS + BSE, $x:$ FOS + SSE. 


\subsection{Specific Changes in Microbial Population}

After $24 \mathrm{~h}$ of in vitro fermentation, the OO group displayed higher abundance of Bacteroidetes than the NW group (Figure 4). We observed relative decrease in Bacteroidetes in all treatments (Table 3). In all subjects BSE resulted in significantly higher abundance of Bacteroidetes at $24 \mathrm{~h}$ than NC and all other treatments $(p<0.05)$ (Figure 4$)$.

(a) Bacteroidetes

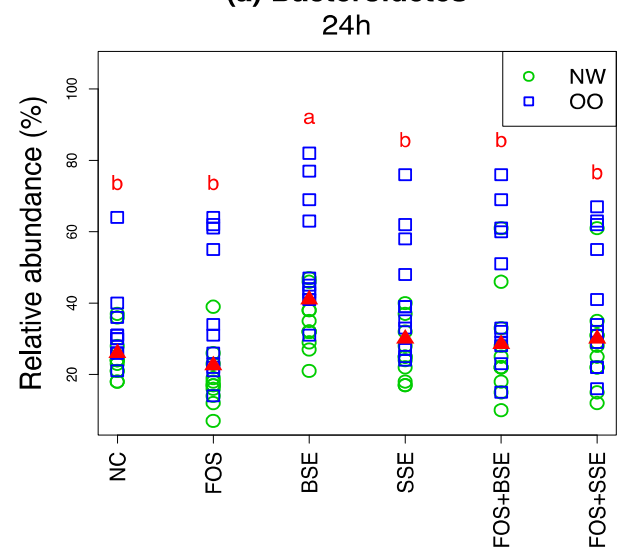

(c) Proteobacteria

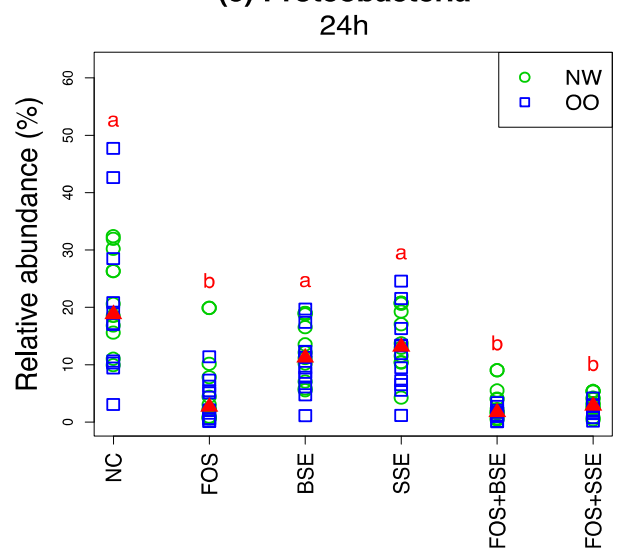

(b) Firmicutes

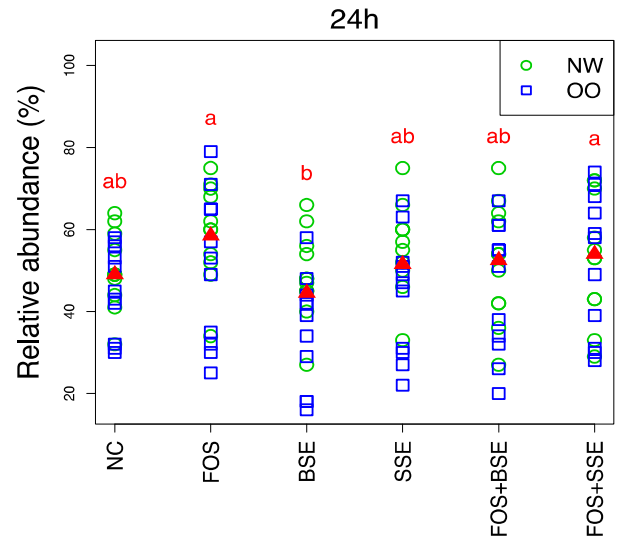

(d) Actinobacteria

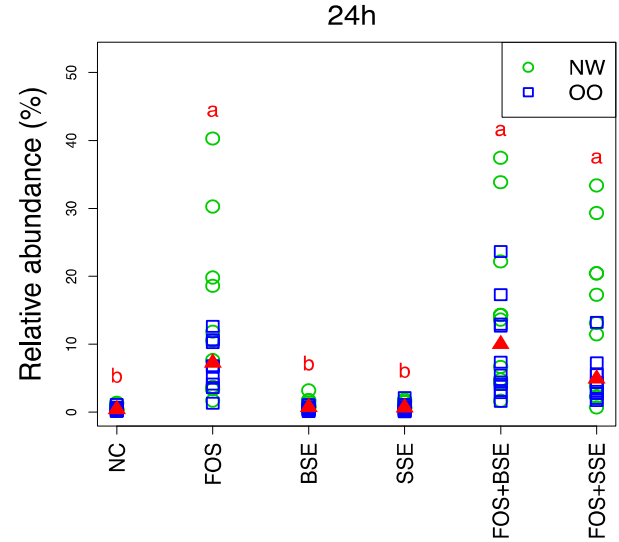

(e) Verrucomicrobia

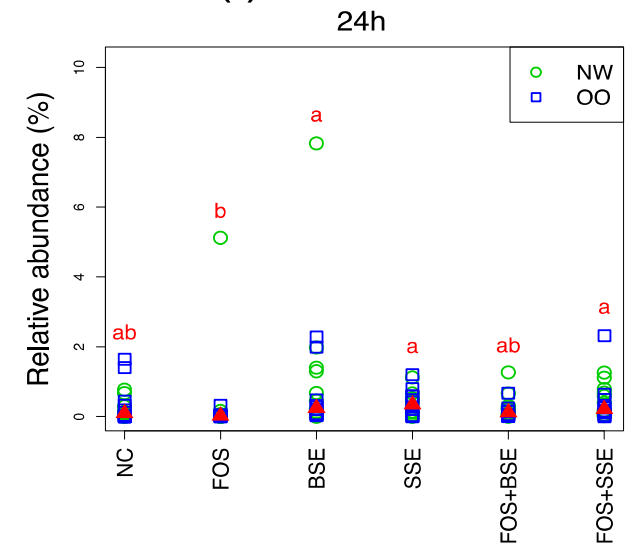

Figure 4. Relative abundance at phylum level $(n=22)$. (a) Bacteroidetes, (b) Firmicutes, (c) Proteobacteria, (d) Actinobacteria, (e) Verrucomicrobia. Letters indicate significant differences between treatments at $24 \mathrm{~h}$, achieved by the Friedman test and its post hoc multiple comparisons at the 0.05 level of significance. The medians are marked with red triangles. The weight classes (NW vs. OO) are labeled by green circles and blue squares, respectively. NC: negative control, FOS: fructooligosaccharides, BSE: black sorghum bran extract, SSE: sumac sorghum bran extract. 
As relative abundance of Bacteroidetes decreased there was a corresponding increase in Firmicutes (Table 3). BSE had significantly lower abundance of Firmicutes at $24 \mathrm{~h}$ compared to FOS and FOS + SSE $(p<0.05)$ (Figure 4).

FOS, FOS + BSE, and FOS + SSE had significantly lower abundance of Proteobacteria after $24 \mathrm{~h}$ compared to NC, BSE, and SSE $(p<0.05)$ (Figure 4 ).

NW tended to display a greater response of Actinobacteria than OO in FOS, FOS + BSE and FOS + SSE (Figure 4). While NC, BSE, and SSE showed negligible increases of Actinobacteria after $24 \mathrm{~h}, \mathrm{FOS}, \mathrm{FOS}+\mathrm{BSE}$ and FOS + SSE increased at significantly higher magnitudes of $10 \%, 12 \%$, and $9 \%$, respectively $(p<0.05)$ (Table 3$)$.

Compared to FOS, relative abundance of Verrucomicrobia increased in BSE, SSE and FOS + SSE after $24 \mathrm{~h}$ of in vitro fermentation $(p<0.05)$ (Figure 4$)$.

Prevotella was present at higher levels in OO than NW in all treatments after $24 \mathrm{~h}$ (Figure 5). Relative abundance of Prevotella decreased about $15 \%$ in the NC but to a lesser extent in all treatments (Table 4). At $24 \mathrm{~h}$, abundance was significantly higher than the NC for BSE, SSE, FOS + BSE and FOS + SSE $(p<0.05)$ but not for FOS alone (Figure 5). Additionally, BSE and FOS + SSE had significant higher levels than FOS $(p<0.05)$ (Figure 5).

(a) Prevotella

$24 \mathrm{~h}$

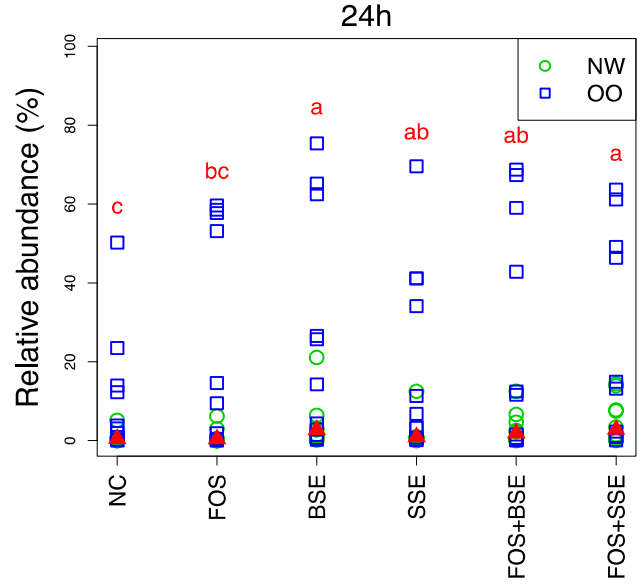

(c) Bifidobacterium

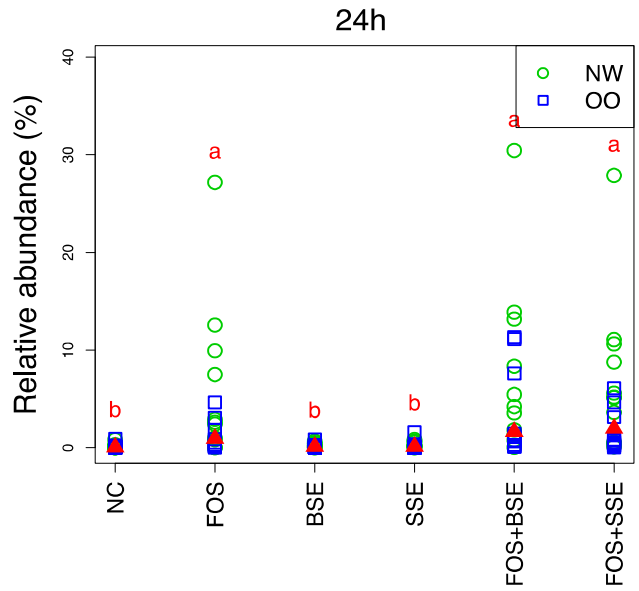

(b) Bacteroides

$24 \mathrm{~h}$

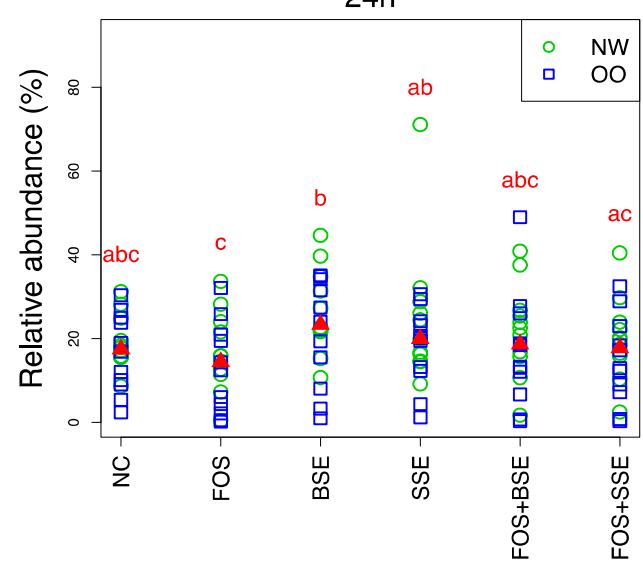

(d) Lactobacillus

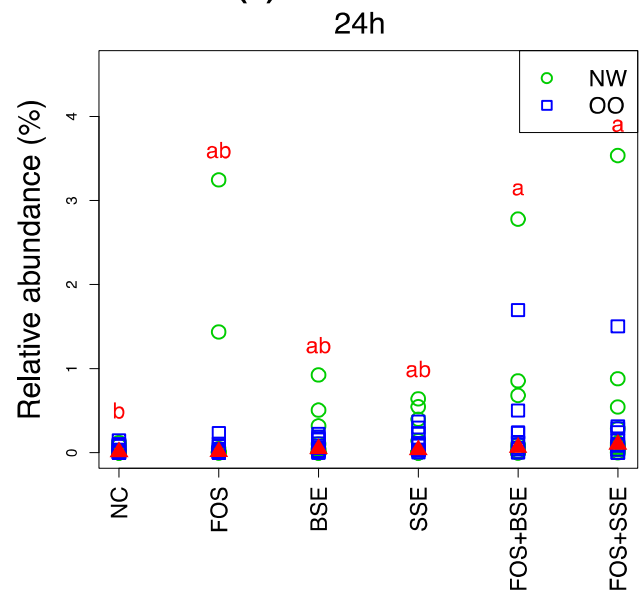

Figure 5. Relative abundance of select genera $(n=22)$. (a) Prevotella, (b) Bacteroides, (c) Bifidobacterium, (d) Lactobacillus. Letters indicate significant differences between treatments at $24 \mathrm{~h}$, achieved by the Friedman test and its post hoc multiple comparisons at 0.05 level of significance. The medians are marked with red triangles. The weight classes (NW vs. OO) are labeled by green circles and blue squares, respectively. NC: negative control, FOS: fructooligosaccharides, BSE: black sorghum bran extract, SSE: sumac sorghum bran extract. 
Though Bacteroides tended to be higher in NW samples, no significant differences were observed between the two groups after $24 \mathrm{~h}$ of in vitro fermentation. Both BSE and SSE resulted in higher abundance of Bacteroides than FOS $(p<0.05)$ (Figure 5).

Samples from NW subjects tended to have higher levels of Bifidobacterium after $24 \mathrm{~h}$ than OO samples when treated with FOS and FOS plus sorghum polyphenols (Figure 5). Bifidobacterium relative abundance in FOS, FOS + BSE, and FOS + SSE was significantly higher than the NC, BSE, and SSE after $24 \mathrm{~h}(p<0.05)$ (Figure 5). Sorghum polyphenols alone had no effect.

There were no significant differences between weight class groups for Lactobacillus. While Lactobacillus relative abundance was stable in the NC after $24 \mathrm{~h}$, increases of this genus, though small, were seen in all treatments (Table 4). While FOS alone did not significantly increase abundance at $24 \mathrm{~h}$ compared to the NC, FOS + BSE and FOS + SSE had significantly higher levels compared to the NC $(p<0.05)$ (Figure 5). Sorghum polyphenols alone did not significantly affect Lactobacillus.

Abundance of Faecalibacterium tended to be higher at $24 \mathrm{~h}$ in NW than OO (Figure 6). There was little change in Faecalibacterium over $24 \mathrm{~h}$ in the NC (Table 4), however abundance decreased in response to all treatments and was significantly lower in FOS, BSE, and FOS + BSE at $24 \mathrm{~h}$ compared to NC, SSE, and FOS + SSE $(p<0.05)$ (Figure 6).

Roseburia was stimulated by sumac sorghum polyphenols, with SSE resulting in higher abundance than NC and FOS at $24 \mathrm{~h}(p<0.05)$ (Figure 6).

(a) Faecalibacterium

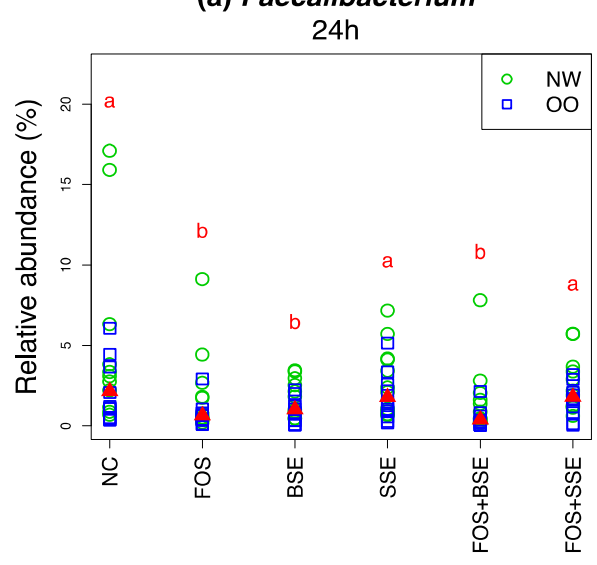

(b) Roseburia

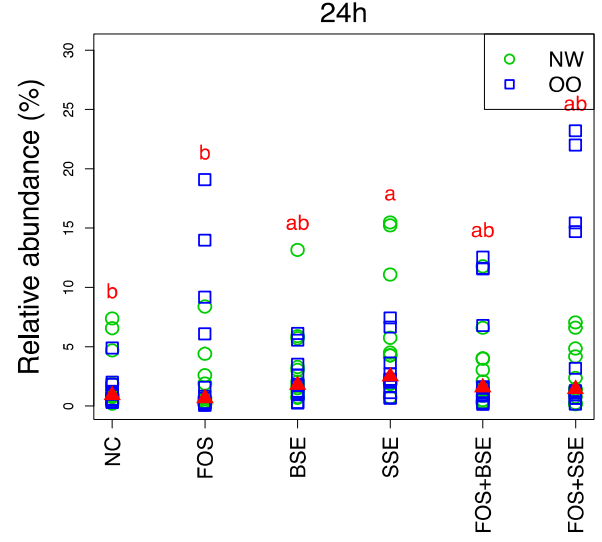

(c) Anaerostipes

$24 \mathrm{~h}$

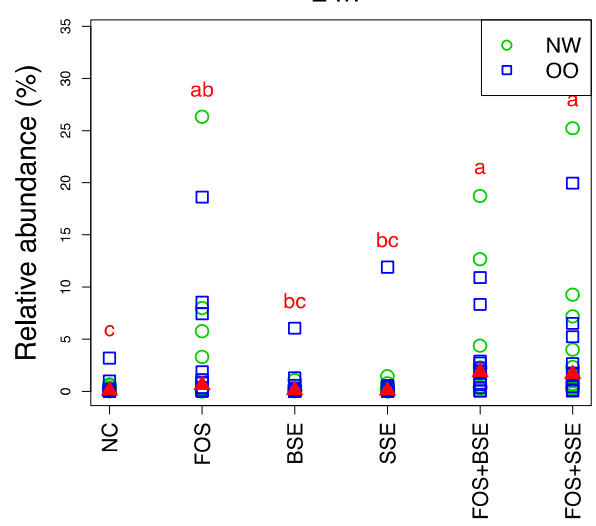

Figure 6. Relative abundance of butyric acid-producing bacteria $(n=22)$. (a) Faecalibacterium, (b) Roseburia, (c) Anaerostipes. Letters indicate significant differences between treatments at $24 \mathrm{~h}$, achieved by the Friedman test and its post hoc multiple comparisons at the 0.05 level of significance. The medians are marked with red triangles. The weight classes (NW vs. OO) are labeled by green circles and blue squares, respectively. NC: negative control, FOS: fructooligosaccharides, BSE: black sorghum bran extract, SSE: sumac sorghum bran extract. 
No significant differences were seen in Anaerostipes between the two weight groups. Relative abundance of Anaerostipes was higher in FOS, FOS + BSE, and FOS + SSE compared to NC at $24 \mathrm{~h}$ $(p<0.05)$ (Figure 6). FOS + BSE and FOS + SSE significantly increased Anaerostipes compared to NC, BSE and SSE $(p<0.05)$ (Figure 6).

\section{Discussion}

As metabolic conditions such as obesity continue to burden large proportions of the U.S. population, the topic of gut health, and more specifically the gut microbiota, has gained increasing attention in the realms of health and nutrition. For this reason, a recent focus of nutrition research has been identifying whole foods as well as bioactive components with the potential to positively shift dysregulated bacterial populations towards more desirable profiles [34]. Of particular allure are plant polyphenols, as they are widely spread in nature and have been credited with the ability to positively modulate the gut microbiota. Not only is grain sorghum bran is a source of polyphenols, but it is also cost effectively and efficiently produced in the United States, making it an attractive candidate for nutraceutical applications.

Our current study found both black and sumac sorghum brans to contain various classes of polyphenols. In sorghum bran analysis, our findings of $27.5 \pm 1.5 \mathrm{mg} / \mathrm{g}$ for black and $43.0 \pm 2.0 \mathrm{mg} / \mathrm{g}$ for sumac are consistent with previous reports of total phenolics ranging from 7.6-35.6 mg/g and $22.5-88.5 \mathrm{mg} / \mathrm{g}$ for black and sumac sorghum bran, respectively $[17,18,35]$. The two varieties had strikingly distinct phenolic profiles, with higher concentrations of 3-Deoxyanthocyanins (3-DXA) in black bran, and higher concentrations of proanthocyanidins in sumac bran. These results are in agreement with multiple previous analyses of black and sumac sorghum, in which black sorghum is established as enriched in 3-DXA, and sumac in proanthocyanidins $[17,18,36,37]$.

It has been well established that grain sorghum bran has significant antioxidant capabilities [17,18,36-39], and our current analyses sought to compare the radical scavenging properties of the two different varieties of sorghum bran extract. Despite lower levels of total polyphenols in black sorghum bran extract (BSE), both BSE and sumac sorghum bran extract (SSE) showed similar radical scavenging capabilities.

Fermentation with the wine/grape and black tea polyphenols resulted in significantly increased acetate concentrations compared to blank in a study by Gross et al. [40]. However, in the present study, the levels of acetate and butyrate did not change during the fermentations with BSE and SSE compared to NC. Propionate production was lower in SSE compared to the NC, which is not in agreement with the report of Gross et al. [40] who found no change of propionate production with the wine/grape and tea polyphenols. FOS-containing treatments in this study increased butyrate production over $24 \mathrm{~h}$. Lactobacillus and Bifidobacterium are both known to utilize FOS to produce lactic acid [41], which can be further metabolized to butyrate by genera such at Anaerostipes and Eubacterium [42]. We found increases in Bifidobacterium, Lactobacillus, and Anaerostipes in response to FOS-containing treatments, so it is plausible that the increases in butyrate were due to these cross-feeding pathways. This is one of the first studies to examine the impact of sorghum bran polyphenols on SCFA production and further work is needed to corroborate these findings.

Although NMDS did not reveal a significant impact of sorghum polyphenols on the overall microbial communities, the sorghum extracts modulated the gut microbiota at both phyla and genus levels, and combined sorghum polyphenols and FOS worked to enhance specific beneficial genera. Our data showed relative shifts in the two major phyla, Firmicutes increasing in abundance and Bacteroidetes decreasing. This is not surprising, as many carbohydrate utilizers, including the probiotic Lactobacillus, are within Firmicutes, and the conditions of the experiment promote utilization of these substrates, including those already present in the fecal samples.

Proteobacteria contains several potentially pathogenic bacteria [43] avoiding the overgrowth of this phylum may be a positive outcome of nutrition strategies. Lower abundance of Proteobacteria likely reflect the increases in groups that utilize FOS. Though not statistically significant, BSE and 
SSE caused a marked decrease in Proteobacteria compared to the NC, suggesting they may act antagonistically against some pathogenic species. These results are similar to those of Pham et al. [44], who found that during in vitro fecal fermentation Proteobacteria was decreased by FOS, feruloylated arabinoxylans (FAXO), proanthocyanidin-rich rice bran polyphenols, and FAXO and rice bran polyphenols combined.

Prevotella is often associated with long-term high carbohydrate diets [45]. Prevotella was stimulated but there were no significant differences between sorghum polyphenols with and without FOS. A study with 62 obese subjects found that individuals with a high Prevotella:Bacteroides ratio lost significantly more weight in response to a high-fiber diet than individuals with lower levels of Prevotella [46]. Although further research is required to reach a deeper understanding of this interaction, enhancing the ratio of Prevotella:Bacteroides may assist in weight-loss strategies that are based on increased fiber intake. In the present study, OO samples resulted in increased Prevotella:Bacteroides with higher levels of Prevotella after $24 \mathrm{~h}$.

Though health-promoting bacterial genera in the colon are not limited to Lactobacillus and Bifidobacterium, they are the traditional targets of prebiotic supplementation [14]. Bifidobacterium proliferation was enhanced by FOS-containing treatments. Compared to the NC, FOS + BSE and FOS + SSE tended to increase abundance of Bifidobacterium in OO. This data suggests utilization of FOS by Bifidobacterium is altered in $\mathrm{OO}$ microbiota, and that sorghum polyphenols may enhance fermentation of FOS by this species in OO subjects. As decreased proportions of Bifidobacterium have been seen previously in overweight/obese subjects [6,7], nutritional therapies to increase this genus may be extremely beneficial to individuals combatting excessive body weight gain. Past in vitro fermentation studies have observed stimulation of Bifidobacterium by polyphenols such as the anthocyanin malvidin-3-glucoside [47], tart cherries [31], and grape and red wine polyphenols [23,48]. In our experiment, however, this genus was not apparently impacted by sorghum polyphenols alone.

In the present study, FOS and sorghum polyphenols worked synergistically to enhance Lactobacillus. As Lactobacillus was present at low abundance, further studies are needed to corroborate these effects. Success of prebiotic research in stimulating growth of Lactobacillus has been markedly lower than with Bifidobacterium [14], and the ability of polyphenols to enhance oligosaccharide utilization by Lactobacillus would provide a new avenue of prebiotic supplementation. As human clinical trials have attributed several strains of Lactobacillus with anti-obesogenic actions [49], this mode of supplementation may be especially beneficial in body weight maintenance. In addition, previous studies have observed stimulation of Lactobacillus by red wine polyphenols, grape seed extract monomers, and anthocyanin malvidin-3-glucoside [19,47,48].

Additional targets of prebiotic supplementation include butyrate-producing bacteria. Butyrate is not only the main energy source of colonocytes, but research has purported numerous roles in colon-cancer antagonism, inflammation suppression, and colonic barrier function [50]. In our study, FOS-containing treatments increased butyrate production and this trend was paralleled by increased abundance of Anaerostipes. Anaerostipes produces butyrate by metabolizing lactate produced by other species or utilizing acetate through the butyryl CoA: acetate CoA transferase pathway [51], and our results suggest that this genus was responsible for much of the butyrate production during this in vitro fermentation.

Roseburia is a genus with the ability to produce butyrate through the butyryl CoA: acetate CoA transferase pathway [52]. Though little research has been done with this genus, reduced abundance of Roseburia has been a marker of dysbiosis in both ulcerative colitis [53] and colorectal cancer [54]. Previous studies have identified stimulation of Roseburia by various carbohydrate sources [55,56], but this was not significantly impacted by FOS-containing treatments in the present study. SSE, on the other hand, caused significant increases compared to both NC and FOS, indicating utilization of sumac sorghum polyphenols by Roseburia. This is not the first report of Roseburia stimulation by polyphenols, as this genus also increased in response to red rice bran polyphenols [44]. 


\section{Conclusions}

Black and sumac sorghum brans are significant sources of polyphenols with diverse polyphenol profiles. Although sorghum extracts did not significantly influence SCFA production from FOS, they enhanced proliferation of Prevotella and the butyrate-producing genus Roseburia. Combined sorghum polyphenols and FOS worked to enhance Bifidobacterium and especially Lactobacillus, a probiotic genus that has been difficult to stimulate through prebiotic supplementation. We observed differential responses to treatment in NW and OO microbiota for Prevotella, Bifidobacterium, and Roseburia, supporting the theory that gut microbial metabolism is altered in OO. Our results indicate that sorghum bran polyphenols may help modulate gut microbial populations, especially in concert with other prebiotic substances such as FOS. Further research is needed to determine which individual polyphenol compound is responsible for beneficial effects on the gut microbiota and to understand the mechanism by which the microbial strains respond to polyphenols.

Author Contributions: S.-O.L. conceived the research project and designed the study; D.A. performed the data collection, laboratory analysis, and wrote manuscript; D.M. and C.B. analyzed the data; J.A.L. and F.C. participated in data analysis and validation. All authors reviewed and edited the manuscript.

Funding: This research was supported by Arkansas Corn and Grain Sorghum Board.

Conflicts of Interest: The authors declare no conflict of interest.

\section{References}

1. Jandhyala, S.M.; Talukdar, R.; Subramanyam, C.; Vuyyuru, H.; Sasikala, M.; Reddy, D.N. Role of the normal gut microbiota. World J. Gastroenterol. 2015, 21, 8787-8803. [CrossRef] [PubMed]

2. Obesity and Overweight. Available online: https://www.cdc.gov/nchs/fastats/obesity-overweight.htm (accessed on 23 September 2018).

3. Adult Obesity Causes \& Consequences. Available online: https://www.cdc.gov/obesity/adult/causes.html (accessed on 23 September 2018).

4. Khan, M.J.; Gerasimidis, K.; Edwards, C.A.; Shaikh, M.G. Role of Gut Microbiota in the Aetiology of Obesity: Proposed Mechanisms and Review of the Literature. J. Obes. 2016, 2016, 7353642. [CrossRef] [PubMed]

5. Collado, M.C.; Isolauri, E.; Laitinen, K.; Salminen, S. Distinct composition of gut microbiota during pregnancy in overweight and normal-weight women1-3. Am. J. Clin. Nutr. 2008, 88, 894-899. [CrossRef] [PubMed]

6. Kalliomaki, M.; Collado, M.C.; Salminen, S.; Isolauri, E. Early differences in fecal microbiota composition in children may predict overweight. Am. J. Clin. Nutr. 2008, 87, 534-538. [CrossRef] [PubMed]

7. Santacruz, A.; Collado, M.C.; García-Valdés, L.; Segura, M.T.; Martin-Lagos, J.A.; Anjos, T.; Romero, M.; Lopez, R.M.; Florido, J.; Campoy, C.; et al. Gut microbiota composition is associated with body weight, weight gain and biochemical parameters in pregnant women. Br. J. Nutr. 2010, 104, 83-92. [CrossRef]

8. Riva, A.; Borgo, F.; Lassandro, C.; Verduci, E.; Morace, G.; Borghi, E.; Berry, D. Pediatric obesity is associated with an altered gut microbiota and discordant shifts in Firmicutes populations. Environ. Microbiol. 2017, 19, 95-105. [CrossRef] [PubMed]

9. Ríos-Covián, D.; Ruas-Madiedo, P.; Margolles, A.; Gueimonde, M.; de los Reyes-Gavilán, C.G.; Salazar, N. Intestinal Short Chain Fatty Acids and their Link with Diet and Human Health. Front. Microbiol. 2016, 7, 185. [CrossRef] [PubMed]

10. Canfora, E.E.; van der Beek, C.M.; Jocken, J.W.E.; Goossens, G.H.; Holst, J.J.; Olde-Damink, S.W.M.; Lenaerts, K.; Dejong, C.H.C.; Blaak, E.E. Colonic infusions of short-chain fatty acid mixtures promote energy metabolism in overweight/obese men: A randomized crossover trial. Sci. Rep. 2017, 7, 2360. [CrossRef]

11. Chambers, E.S.; Viardot, A.; Psichas, A.; Morrison, D.J.; Murphy, K.; Zac-Varghese, S.E.K.; MacDougall, K.; Preston, T.; Tedford, C.; Finlayson, G.S.; et al. Effects of targeted delivery of propionate to the human colon on appetite regulation, body weight maintenance and adiposity in overweight adults. Gut 2015, 64, 1744-1754. [CrossRef] [PubMed] 
12. Rossi, M.; Corradini, C.; Amaretti, A.; Nicolini, M.; Pompei, A.; Zanoni, S.; Matteuzzi, D. Fermentation of Fructooligosaccharides and Inulin by Bifidobacteria: A Comparative Study of Pure and Fecal Cultures. Appl. Environ. Microbiol. 2005, 71, 6150-6158. [CrossRef]

13. Gibson, G.R.; Scott, K.P.; Rastall, R.A.; Tuohy, K.M.; Hotchkiss, A.; Dubert-Ferandon, A.; Gareau, M.; Murphy, E.F.; Saulnier, D.; Loh, G.; et al. Dietary prebiotics: Current status and new definition. Food Sci. Technol. 2010, 7, 1-19. [CrossRef]

14. Gibson, G.R.; Hutkins, R.; Sanders, M.E.; Prescott, S.L.; Raylene, R.A.; Salminem, S.J.; Scott, K.; Stanton, C.; Swanson, K.S.; Cani, P.D.; et al. The International Scientific Association for Probiotics and Prebiotics (ISAPP) consensus statement on the definition and scope of prebiotics. Nat. Rev. 2017, 14, 491-502.

15. Pandey, K.B.; Rizvi, S.I. Plant polyphenols as dietary antioxidants in human health and disease. Oxid. Med. Cell. Longev. 2009, 25, 270-278. [CrossRef] [PubMed]

16. Manach, C.; Scalbert, A.; Morand, C.; Rémésy, C.; Jiménez, L. Polyphenols: Food sources and bioavailability. Am. J. Clin. Nutr. 2004, 79, 727-747. [CrossRef] [PubMed]

17. Awika, J.M.; McDonough, C.M.; Rooney, L.W. Decorticating Sorghum to Concentrate Healthy Phytochemicals. J. Agric. Food Chem. 2005, 53, 6230-6234. [CrossRef] [PubMed]

18. Awika, J.M.; Rooney, L.W. Properties of 3-deoxyanthocyanins from Sorghum. J. Agric. Food Chem. 2004, 52, 4388-4394. [CrossRef] [PubMed]

19. Cueva, C.; Sánchez-Patán, F.; Monagas, M.; Walton, G.E.; Gibson, G.R.; Martín-Álvarez, P.J.; Bartolomé, B.; Moreno-Arribas, M.V. In vitro fermentation of grape seed flavan-3-ol fractions by human faecal microbiota: Changes in microbial groups and phenolic metabolites. FEMS Microbiol. Ecol. 2013, 83, 792-805. [CrossRef]

20. Anhê, F.F.; Roy, D.; Pilon, G.; Dudonné, S.; Matamoros, S.; Varin, T.V.; Garofalo, C.; Moine, Q.; Desjardins, Y.; Levy, E.; Marette, A. A polyphenol-rich cranberry extract protects from diet-induced obesity, insulin resistance and intestinal inflammation in association with increased Akkermansia spp. population in the gut microbiota of mice. Gut 2015, 64, 872-883.

21. Roopchand, D.E.; Carmody, R.N.; Kuhn, P.; Moskal, K.; Rojas-Silva, P.; Turnbaugh, P.J.; Raskin, I. Dietary Polyphenols Promote Growth of the Gut Bacterium Akkermansia muciniphila and Attenuate High-Fat Diet-Induced Metabolic Syndrome. Diabetes 2015, 64, 2847-2858. [CrossRef]

22. Song, H.; Chu, Q.; Yan, F.; Yang, Y.; Han, W.; Zheng, X. Red pitaya betacyanins protects from diet-induced obesity, liver steatosis and insulin resistance in association with modulation of gut microbiota in mice. J. Gastroenterol. Hepatol. 2016, 31, 1462-1469. [CrossRef]

23. Zhou, L.; Wang, W.; Huang, J.; Ding, Y.; Pan, Z.; Zhao, Y.; Zhang, R.; Hu, B.; Zeng, X. In vitro extraction and fermentation of polyphenols from grape seeds (Vinis vinifera) by human intestinal microbiota. Food Funct. 2016, 7, 1959-1967. [CrossRef] [PubMed]

24. Neyrinck, A.M.; Etxeberria, U.; Taminiau, B.; Daube, G.; Van Hul, M.; Everard, A.; Cani, P.D.; Bindels, L.B.; Delzenne, N.M. Rhubarb extract prevents hepatic inflammation induced by acute alcohol intake, an effect related to the modulation of the gut microbiota. Mol. Nutr. Food Res. 2016, 61, 1500899. [CrossRef] [PubMed]

25. Singleton, V.L.; Rossi, J.A. Colorimetry of Total Phenolics with Phosphomolybdic-Phosphotungstic Acid Reagents. Am. J. Enol. Vitic. 1965, 16, 144-158.

26. Payne, M.J.; Hurst, W.J.; Stuart, D.A.; Ou, B.; Fan, E.; Ji, H.; Kou, Y. Determination of Total Procyanidins in Selected Chocolate and Confectionary Products Using DMAC. J. AOAC Int. 2009, 93, 89-96.

27. Cho, M.J.; Howard, L.R.; Prior, R.L.; Clark, J.R. Flavonoid glycosides and antioxidant capacity of various blackberry, blueberry and red grape genotypes determined by high-performance liquid chromatography/mass spectrometry. J. Sci. Food Agric. 2004, 84, 1771-1782. [CrossRef]

28. Brand-Williams, W.; Cuvelier, M.E.; Berset, C. Use of a free radical method to evaluate antioxidant activity. Lebensm. Wiss. Technol. 1995, 28, 25-30. [CrossRef]

29. Yang, J.; Keshavarzian, A.; Rose, D.J. Impact of dietary fiber fermentation from cereal grains on metabolite production by the fecal microbiota from normal weight and obese individuals. J. Med. Food 2013, 16, 862-867. [CrossRef]

30. Bourquin, L.D.; Titgemeyer, E.C.; Fahey, G.C. Vegetable Fiber Fermentation by Human Fecal Bacteria: Cell Wall Polysaccharide Disappearance and Short-Chain Fatty Acid Production during In Vitro Fermentation and Water-Holding Capacity of Unfermented Residues. Nutr. Metab. 1993, 123, 860-869. [CrossRef] 
31. Mayta-Apaza, A.; Pottgen, E.; de Bodt, J.; Papp, N.; Daya, M.; Luke, H.; Abranko, L.; VandeWiele, T.; Lee, S.O.; Carbonero, F. Impact of tart cherry polyphenols on the human gut microbiota and phenolic metabolites in vitro and in vivo. J. Nutr. Biochem. 2018, 59, 170-172. [CrossRef]

32. Kozich, J.J.; Westcott, S.L.; Baxter, N.T.; Highlander, S.K.; Schloss, P.D. Development of a dual-index sequencing strategy and curation pipeline for analyzing amplicon sequence data on the MiSeq Illumina sequencing platform. Appl. Environ. Microbiol. 2013, 79, 5112-5120. [CrossRef]

33. Schloss, P.D.; Westcott, S.L.; Ryabin, T.; Hall, J.R.; Hartmann, M.; Hollister, E.B.; Lesniewski, R.A.; Oakley, B.B.; Parks, D.D.; Robinson, C.J.; et al. Introducing mothur: Open-source, platform-independent, community-supported software for describing and comparing microbial communities. Appl. Environ. Microbiol. 2009, 75, 7537-7541. [CrossRef] [PubMed]

34. Sheflin, A.M.; Melby, C.L.; Carbonero, F.; Weir, T.L. Linking dietary patterns with gut microbial composition and function. Gut Microbes 2017, 8, 113-129. [CrossRef] [PubMed]

35. Awika, J.M.; Rooney, L.W. Sorghum phytochemicals and their potential impact on human health. Phytochemistry 2004, 65, 1199-1221. [CrossRef] [PubMed]

36. Awika, J.M.; Rooney, L.W.; Wu, X.; Prior, R.L.; Cisneros-Zevallos, L. Screening Methods to Measure Antioxidant Activity of Sorghum (Sorghum bicolor) and Sorghum Products. J. Agric. Food Chem. 2003, 51, 6657-6662. [CrossRef] [PubMed]

37. Dykes, L.; Rooney, L.W.; Waniska, R.D.; Rooney, W.L. Phenolic Compounds and Antioxidant Activity of Sorghum Grain of Varying Phenotypes. J. Agric. Food Chem. 2005, 53, 6813-6818. [CrossRef] [PubMed]

38. Kamath, V.G.; Chandrashekar, A.; Rajini, P.S. Antiradical properties of sorghum (Sorghum bicolor L. Moench) flour extracts. J. Cereal Sci. 2005, 40, 283-288. [CrossRef]

39. Kil, H.W.; Seong, E.S.; Ghimire, B.K.; Chung, I.M.; Kwon, S.S.; Goh, E.J.; Heo, K.; Kim, M.J.; Lim, J.D.; Lee, D.; et al. Antioxidant and antimicrobial activities of crude sorghum extract. Food Chem. 2009, 115, 1234-1239. [CrossRef]

40. Gross, G.; Jacobs, D.M.; Peters, S.; Possemiers, S.; van Duynhoven, J.; Vaughan, E.E.; van de Wiele, T. In vitro bioconversion of polyphenols from black tea and red wine/grape juice by human intestinal microbiota displays strong interindividual variability. J. Agric. Food Chem. 2010, 58, 10236-10246. [CrossRef]

41. Kaplan, H.; Hutkins, R.W. Fermentation of Fructooligosaccharides by Lactic Acid Bacteria and Bifidobacteria. Appl. Environ. Microbiol. 2000, 66, 2682-2684. [CrossRef]

42. Duncan, S.H.; Louis, P.; Flint, H.J. Lactate-Utilizing Bacteria, Isolated from Human Feces, That Produce Butyrate as a Major Fermentation Product. Appl. Environ. Microbiol. 2004, 70, 5810-5817. [CrossRef]

43. Shin, N.R.; Whon, T.W.; Bae, J.W. Proteobacteria: Microbial signature of dysbiosis in gut microbiota. Trends Microbiol. 2015, 33, 496-503. [CrossRef] [PubMed]

44. Pham, T.; Savary, B.J.; Teoh, K.; Chen, M.H.; McClung, A.; Lee, S.O. In Vitro Fermentation Patterns of Rice Bran Components by Human Gut Microbiota. Nutrients 2017, 9, 1237. [CrossRef] [PubMed]

45. Wu, G.D.; Chen, J.; Hoffmann, C.; Bittinger, K.; Chen, Y.Y.; Keilbaugh, S.A.; Bewtra, M.; Knights, D.; Walters, W.A.; Knight, R.; et al. Linking Long-Term Dietary Patterns with Gut Microbial Enterotypes. Science 2011, 334, 105-108. [CrossRef] [PubMed]

46. Hjorth, M.F.; Roager, H.M.; Larsen, T.M.; Poulsen, S.K.; Licht, T.R.; Bahl, M.I.; Zohar, Y.; Astrup, A. Pre-treatment microbial Prevotella-to-Bacteroides ration, determines body fat loss success during a 6-month randomized controlled diet intervention. Int. J. Obes. 2018, 42, 580-583. [CrossRef] [PubMed]

47. Hidalgo, M.; Oruna-Concha, M.J.; Kolida, S.; Walton, G.E.; Kallithraka, S.; Spencer, J.P.E.; Gibson, G.R.; de Pascual-Teresa, S. Metabolism of Anthocyanins by Human Gut Microbiota and Their Influence on Gut Bacterial Growth. J. Agric. Food Chem. 2012, 60, 3882-3890. [CrossRef] [PubMed]

48. Dolara, P.; Luceri, C.; De Filippo, C.; Femia, A.P.; Giovannelli, L.; Caderni, G.; Cecchini, C.; Silvi, S.; Orpianesi, C.; Cresci, A. Red wine polyphenols influence carcinogenesis, intestinal microflora, oxidative damage and gene expression profiles of colonic mucosa in F344 rats. Mutat. Res. 2005, 591, 237-246. [CrossRef] [PubMed]

49. Crovesy, L.; Ostrowski, M.; Ferreira, D.M.T.P.; Rosado, E.L.; Soares-Mota, M. Effect of Lactobacillus on body weight and body fat in overweight subjects: A systematic review of randomized controlled clinical trials. Int. J. Obes. 2017, 41, 1607-1614. [CrossRef] [PubMed]

50. Hamer, H.M.; Jonker, D.; Venema, K.; Vanhoutvin, S.; Troost, F.J.; Brummer, R.J. Review Article: The role of butyrate on colonic function. Aliment. Pharmacol. Therap. 2008, 27, 104-119. [CrossRef] 
51. Louis, P.; Flint, H.J. Formation of propionate and butyrate by the human colonic bacteria. Environ. Microbiol. 2016, 19, 29-41. [CrossRef]

52. Duncan, S.H.; Hold, G.L.; Barcenilla, A.; Stewart, C.S.; Flint, H.J. Roseburia intestinalis sp. nov., a novel saccharolytic, butyrate-producing bacterium from human faeces. Int. J. Syst. Evol. Microbiol. 2002, 52, 1615-1620.

53. Machiels, K.; Joosens, M.; Sabino, J.; De Preter, V.; Arijs, I.; Eeckhaut, V.; Ballet, V.; Claes, K.; Van Immerseel, F.; Verbeke, K.; et al. A decrease of the butyrate-producing species Roseburia hominis and Faecalibacterium prausnitzii defines dysbiosis in patients with ulcerative colitis. Gut 2014, 63, 1275-1283. [CrossRef] [PubMed]

54. Wang, T.; Cai, G.; Qiu, Y.; Fei, N.; Zhang, M.; Pang, X.; Jia, W.; Cai, S.; Zhao, L. Structural segregation of gut microbiota between colorectal cancer patients and healthy volunteers. ISME J. 2012, 6, 320-329. [CrossRef] [PubMed]

55. Neyrinck, A.M.; Possemiers, S.; Verstraete, W.; De Backer, F.; Cani, P.D.; Delzenne, N.M. Dietary modulation of clostridial cluster XIVa gut bacteria (Roseburia spp.) by chitin-glucan fiber improves host metabolic alterations induced by high-fat diet in mice. J. Nutr. Biochem. 2012, 23, 51-59. [CrossRef] [PubMed]

56. Neyrinck, A.M.; Possemiers, S.; Druart, C.; Van de Wiele, T.; de Backer, F.; Cani, P.D.; Larondelle, Y.; Delzenne, N.M. Prebiotic Effects of Wheat Arabinoxylan Related to the Increase in Bifidobacteria, Roseburia and Bacteroides/Prevotella in Diet-Induced Obese Mice. PLoS ONE 2011, 6, e20944. [CrossRef] [PubMed]

(C) 2019 by the authors. Licensee MDPI, Basel, Switzerland. This article is an open access article distributed under the terms and conditions of the Creative Commons Attribution (CC BY) license (http:/ / creativecommons.org/licenses/by/4.0/). 